\title{
Synthesis and Characterization of Al-TON Zeolite Using a Dialkylimizadolium as Structure- Directing Agent
}

\author{
Christian Wittee Lopes ${ }^{a}$, Jhonny Villarroel-Rocha ${ }^{b}$, Bernardo Araldi Da Silva ${ }^{c}$, \\ Marcelo Luis Mignonic, Sibele Berenice Castellã Pergher ${ }^{a}$ \\ ${ }^{a}$ Universidade Federal do Rio Grande do Norte - UFRN, Avenida Senador Salgado Filho, 3000, CEP \\ 59078-970, Natal, RN, Brazil \\ ${ }^{b}$ Laboratório de Sólidos Porosos, Instituto de Física Aplicada, Universidad Nacional de San Luis, \\ Chacabuco, San Luis, Argentina \\ ${ }^{c}$ Universidade Regional Integrada, Campus de Erechim, Avenida Sete de Setembro, 1621, \\ CEP 99709-910, Erechim, RS, Brazil
}

Received: January 20, 2016; Revised: September 17, 2016; Accepted: October 20, 2016

\begin{abstract}
In this work, the synthesis of zeolites using 1-butyl-3-methylimidazolium chloride $\left[\mathrm{C}_{4} \mathrm{MI}\right] \mathrm{Cl}$ as a structure-directing agent was investigated. The organic cation shows effectiveness and selectivity for the syntheses of TON zeolites under different reaction conditions compared to the traditional structuredirecting agent, 1,8-diaminooctane. The 1-butyl-3-methylimidazolium cation lead to highly crystalline materials and its role as OSDA in our synthesis conditions has been confirmed by characterization techniques. ICP-OES confirms the presence of Al in the samples and ${ }^{27} \mathrm{Al}$ MAS NMR analysis indicated that aluminum atoms were incorporated in tetrahedral coordination. Scanning electron microscopy indicated that changing the crystallization condition (static or stirring), zeolites with different crystal size were obtained, which consequently affects the textural properties of the zeolites. Moreover, varying some synthesis parameters MFI zeolite can also be obtained.
\end{abstract}

Keywords: 1-butyl-3-methylimidazolium, zeolite synthesis, TON zeolite

\section{Introduction}

Zeolites belong to a family of inorganic porous materials (synthetic or natural) with well-defined pores/channels of molecular dimensions, generally in the size range of micropores $(\leq 2 \mathrm{~nm})$. This definition was recently expanded with the discovering of some special extra-large pore zeolites as, for example, ITQ-37' (a mesoporous chiral zeolite) and ITQ- $43^{2}$ (hierarchical meso-microporous zeolite), with pore size in the range of 2-4 nm. The zeolite structure is based on $\mathrm{TO}_{4}$ units in which $\mathrm{T}$ ( $\mathrm{Si}, \mathrm{Al}, \mathrm{Ti}, \mathrm{Ge}$, etc.) is coordinated to four oxygen atoms in a tetrahedral geometry. In addition to the molecular sieving, the presence of heteroatoms in different zeolitic structures may confer different properties to the zeolites, such as acidity, ion exchange, redox properties, among others. ${ }^{3-7}$ Certain zeolites require organic molecules (organic structure-directing agent, OSDA) for their crystallization to be thermodynamically favorable, and several molecule groups have been studied..$^{8-10}$ Depending on the characteristics of these organic molecules (size, flexibility, and hydrophobicity), zeolites with different structural characteristics can be obtained. ${ }^{11-14}$ Imidazolium compounds (generally known as ionic liquids) have gained attention in recent years because their structures are similar to traditional used OSDA and they possess high thermal stability, negligent vapor pressure, the

*e-mail: chriswittee@gmail.com possibility of modification and environmental appeal. ${ }^{14-16}$ The zeolites with TON topology are one-dimensional silicon-rich medium pore zeolites $(0.57 \times 0.46 \mathrm{~nm})$, which require an organic molecule as the OSDA for its crystallization. Wen et al. ${ }^{17}$ studied the influence of alkyl chain length on the structure-directing effect of alkylimidazolium ionic liquids and showed that 1-butyl-3-methylimidazolium is the most suitable ionic liquid to TON zeolite synthesis. This behavior was attributed to the similar length size of the zeolite structure channel and the 1-butyl-3-methylimidazolium. ${ }^{17}$ Recently, our group published the synthesis of $\mathrm{TiO}_{2}$-containing TON zeolites using 1-butyl-3-methylimidazolium chloride $\left(\left[\mathrm{C}_{4} \mathrm{MI}\right]\right.$ $\mathrm{Cl}$ ) as OSDA and the effectiveness of this ionic liquid was confirmed ${ }^{18}$ In this study, we describe the efficient use of a 1-butyl-3-methylimidazolium ionic liquid (Figure 1) as the OSDA in the hydrothermal synthesis of Al-TON zeolites under different crystallization conditions. A traditional synthesis using 1,8-diaminooctane as the structure-directing agent was performed for comparison purposes.

\section{Experimental}

The 1-butyl-3-methylimidazolium was synthesized in its chloride form according to a previously published procedure. ${ }^{19}$ In a typical reaction, 1-methylimidazole (1 mol) and 1-chlorobutane $(1.1 \mathrm{~mol})$ were dissolved in acetonitrile 


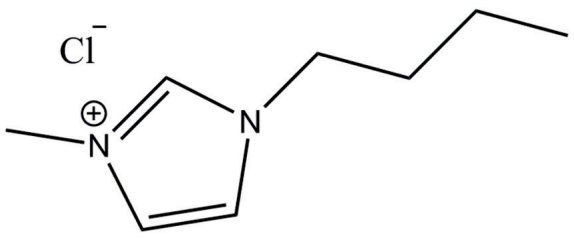

Figure 1: 1-Butyl-3-methylimidazolium chloride ionic liquid

and subjected to stirring under reflux for $48 \mathrm{~h}$ at $80^{\circ} \mathrm{C}$. Ionic liquid crystallization was performed by adding the $\left[\mathrm{C}_{4} \mathrm{MI}\right]$ $\mathrm{Cl}$ solution to a balloon containing ethyl acetate followed by storage of the solution in a freezer for $24 \mathrm{~h}$. The resulting solid was dried under reduced pressure until a constant weight was achieved. The reaction yield was $75 \%$. The ionic liquid obtained was characterized by ${ }^{1} \mathrm{H}$ and ${ }^{13} \mathrm{C}$ liquid NMR (omitted for the sake of brevity), and the spectra were collected on a Varian Inova instrument operating at 300

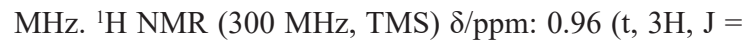
$7.3 \mathrm{~Hz}), 1.38$ (m, 2H), 1.91 (m, 2H), 4.14 (s, 3H), 4.34 (t, $2 \mathrm{H}, \mathrm{J}=7.4 \mathrm{~Hz}), 7.57(\mathrm{~s}, 1 \mathrm{H}), 7.74(\mathrm{~s}, 1 \mathrm{H})$ and $10.6(\mathrm{~s}, 1 \mathrm{H})$. ${ }^{13} \mathrm{C} \mathrm{NMR}\left(300 \mathrm{MHz}, \mathrm{CDCl}_{3}\right) \delta / \mathrm{ppm}: 12.78,18.93,31.64$, $36.14,49.26,121.8,123.44$ and 136.97. These results are consistent with data in the literature for this ionic liquid. ${ }^{19}$ All chemicals were used without further purification.

\subsection{Zeolite synthesis - method A}

The synthesis of zeolites by method $\mathrm{A}^{20}$ was performed by mixing $\mathrm{SiO}_{2}(47.65 \mathrm{~g}$ of Ludox AS-30), [C $\mathrm{CI}] \mathrm{Cl}$ or 1,8-diaminooctane (98\%, Aldrich), $\mathrm{Al}_{2}\left(\mathrm{SO}_{4}\right)_{3} .18 \mathrm{H}_{2} \mathrm{O}(1.76$ g, Sigma-Aldrich), $\mathrm{KOH}$ (4 g, Aldrich), and $\mathrm{H}_{2} \mathrm{O}$ (130 g). After the formation of the synthesis gel, it was aged for $24 \mathrm{~h}$. Subsequently, three equal volumes of the gel were poured into $60-\mathrm{mL}$ Teflon-lined stainless steel autoclaves and stored in an oven at $160{ }^{\circ} \mathrm{C}$ from $24 \mathrm{~h}$ to 7 days either without stirring or with mechanical stirring $(60 \mathrm{rpm})$. In the synthesis employing the ionic liquid, the aging step was not performed. After crystallization, the solids were filtered out and washed with water and acetone, and the samples were dried at $100^{\circ} \mathrm{C}$ overnight. The synthesis yield was $7.5 \mathrm{~g}$. The corresponding molar composition of the gels is as follows: $\mathrm{SiO}_{2}: 0.01 \mathrm{Al}_{2} \mathrm{O}_{3}: 0.09 \mathrm{~K}_{2} \mathrm{O}: 0.03 \mathrm{~K}_{2} \mathrm{SO}_{4}: 0.30$ OSDA : $39.86 \mathrm{H}_{2} \mathrm{O}$. To a better understanding, the samples obtained after 3 days in stirring and after 7 days in static were labeled as TON-1 and TON-2, respectively.

\subsection{Zeolite synthesis - method B}

In the method $\mathrm{B}^{14}$, other silica, alumina and mineralizing agent sources were used and the synthesis was performed by mixing $\mathrm{SiO}_{2}$ (18 $\mathrm{g}$ of Aerosil 200, Degussa), [C $\left.\mathrm{C}_{4} \mathrm{MI}\right] \mathrm{Cl}$ (8.16 g), $\mathrm{Na}_{2} \mathrm{Al}_{2} \mathrm{O}_{4}$ (0.58 g, Riedel-de-Haen), NaOH (2.44 g Aldrich), and $\mathrm{H}_{2} \mathrm{O}(130 \mathrm{~g})$. The mixture was stirred for 15 min, then three equal volumes of the gel were poured into 60-mL Teflon-lined stainless steel autoclaves and stored in an oven at $160{ }^{\circ} \mathrm{C}$ for $24 \mathrm{~h}$ to 7 days either without stirring or with mechanical stirring $(60 \mathrm{rpm})$. After the reaction, the solids were filtered out and washed with water and acetone, and the samples were dried at $100{ }^{\circ} \mathrm{C}$ overnight. The synthesis yield was $10 \mathrm{~g}$. The corresponding molar composition of the gels is as follows: $\mathrm{SiO}_{2}: 0.01 \mathrm{Al}_{2} \mathrm{O}_{3}: 0.15$ OSDA : 0.11 $\mathrm{Na}_{2} \mathrm{O}: 24.1 \mathrm{H}_{2} \mathrm{O}$.

\subsection{Characterization of the materials}

The characterizations regarding textural and structural properties were carried out using calcined materials. The solids were calcined at $600{ }^{\circ} \mathrm{C}$ for $5 \mathrm{~h}$ in a muffle furnace at a heating rate of $5{ }^{\circ} \mathrm{C} \mathrm{min}^{-1}$. Structural parameters were evaluated by $\mathrm{X}$-ray diffraction on a Bruker D2 Phaser instrument using $\mathrm{CuK} \alpha$ $(\lambda=0.154 \mathrm{~nm})$ radiation with a Ni filter, a step size of 0.02 , a current of $10 \mathrm{~mA}$, a voltage of $30 \mathrm{kV}$, and a Lynxeye detector. The ${ }^{13} \mathrm{C}$ CP MAS (solid state) and liquid NMR were performed on an Agilent $500 \mathrm{MHz}$ model DD2 operating at $125.7 \mathrm{MHz}$ and Varian Inova operating at $300 \mathrm{MHz}$, respectively. The morphology of the samples was studied by scanning electron microscopy (SEM) using a JEOL JSM-6300 microscope and by field emission scanning electron microscopy (FESEM) using a ZEISS Ultra-55 microscope. ${ }^{27} \mathrm{Al}$ MAS NMR spectra were recorded in a Bruker AV 400 spectrometer at $104.2 \mathrm{MHz}$ with a spinning rate of $10 \mathrm{kHz}$ and a $9^{\circ}$ pulse length of $0.5 \mu \mathrm{s}$ with a $1 \mathrm{~s}$ repetition time. ${ }^{27} \mathrm{Al}$ chemical shifts was referenced to $\mathrm{Al}^{3+}\left(\mathrm{H}_{2} \mathrm{O}\right)_{6}$. The chemical analyses were carried out in a Varian 715-ES ICP - Optical Emission Spectrometer, after solid dissolution in $\mathrm{HNO}_{3} / \mathrm{HCl} / \mathrm{HF}$ aqueous solution. The organic content of the as-made materials was determined by elemental analysis performed with a SCHN FISONS elemental analyzer. Textural properties were determined from $\mathrm{N}_{2}$ adsorption isotherms at $-196{ }^{\circ} \mathrm{C}$ obtained with a Micromeritics ASAP 2420 manometric adsorption equipment. In order to study of the narrow micropores $(<1 \mathrm{~nm})$ of the zeolites, high resolution $\mathrm{CO}_{2}$ adsorption isotherms at $0{ }^{\circ} \mathrm{C}$ up to $100 \mathrm{kPa}$ were measured in a Micromeritics ASAP 2010 manometric adsorption instrument, where the temperature $(0$ ${ }^{\circ} \mathrm{C}$ ) was controlled by means of a thermostatic Julabo F32-HL bath. The samples were previously degassed at $400{ }^{\circ} \mathrm{C}$ for 10 h. The specific surface area was determined with the BET (Brunauer-Emmett-Teller) method ${ }^{21}$ using $\mathrm{N}_{2}$ adsorption data in the range of relative pressures $\left(p / p^{0}\right)$ from 0.005 to 0.04 . The micropore volumes $\left(\mathrm{V}_{\mu \mathrm{p}}-\mathrm{N}_{2}\right.$ and $\left.\mathrm{V}_{\mu \mathrm{p}}-\mathrm{CO}_{2}\right)$ were estimated using the Dubinin-Radushkevich (DR) equation ${ }^{22}$ in the range of $p / p^{0}$ from 0.005 to 0.04 and 0.0004 to 0.03 for $\mathrm{N}_{2}$ and $\mathrm{CO}_{2}$ adsorption, respectively. The total pore volume (TPV) was determined using the Gurvich's rule at a $p / p^{0}$ of $0.97 .{ }^{22}$ The pore volumes were calculated assuming values of density of the adsorbed phase equal to 0.808 and $1.023 \mathrm{~g} / \mathrm{cm}^{3}$ for $\mathrm{N}_{2}$ at 
$-196{ }^{\circ} \mathrm{C}$ and $\mathrm{CO}_{2}$ at $0{ }^{\circ} \mathrm{C}$, respectively. The micropore size distribution was obtained using the Horváth-Kawazoe (HK) method for cylindrical pores ${ }^{23}$ from $\mathrm{CO}_{2}$ adsorption data, where the physical parameters of the adsorbent used were those corresponding to an aluminosilicate.

\section{Results and Discussion}

Figure 2 shows the results from the synthesis method A, using 1,8-diaminooctane as OSDA. The X-ray diffraction patterns (XRD) of the samples revealed differences between the crystallization modes (stirring and static) in the formation of zeolites. In the static mode (samples a-c), it is possible to verify the presence of indexable reflections (unknown phase) only on the third day. Under stirring conditions (samples d-f), it is possible to observe the existence of well-defined reflections relative to TON zeolite (each peak indexed in the figure) without the simultaneous presence of other zeolitic phases after two days. The characteristic reflections of the TON phase are located at $2 \theta$ angles of $8.17,10.15,12.8,16.3,19.4,20.3$, 24.2, 24.6 and 25.7.

In the XRD of Figure 3 (using the ionic liquid as OSDA - method A), it is possible to observe a different behavior in the crystallization of zeolites compared to the synthesis using 1,8-diaminooctane. In the static mode (samples a-d), well-defined peaks from the TON zeolites are present already on the second day of synthesis and are maintained until the seventh day without the appearance of other phases. When stirring is employed (samples e-g), the TON phase is obtained after one day, but the formation of the zeolite prior to one day (behavior already reported by Lopes ${ }^{18}$ ) is not discarded. The XRD patterns of samples obtained in three and seven days in static were normalized (marked with *) for better visualization.
These results show that when $\left[\mathrm{C}_{4} \mathrm{MI}\right] \mathrm{Cl}$ is used as the structure-directing agent, the zeolite crystallizes faster, both in stirring and static modes and without aging the synthesis gel (however, in the IZA methodology, it is debatable whether the aging step is beneficial) ${ }^{20}$. This behavior could be explained by the strong interaction of the charge of the ionic liquid with the zeolitic charge imposed by aluminum, whereas the 1,8-diaminooctane possibly interacts by van der Waals forces, without compensating for the charges of the zeolite framework. Sousa-Júnior et al. ${ }^{24}$ reported the crystallization of TON zeolites using colloidal and pyrolytic silica in which crystallization only occurred when using a stirred system. Muraza et al. ${ }^{25}$ reported the ability to synthesize TON zeolites in less than 24 hours by employing a microwave in the crystallization step; however, the materials were not fully crystalline within 24 hours. In our synthesis (method A), by changing the structure-directing agent and using typical hydrothermal conditions, materials in a fully crystalline state were formed in 24 hours. We are capable to synthesize TON zeolite in traditional approaches in reduced time by our methodology. However, it is important stress that when the synthesis reactants are different the comparison needs to be careful in all cases.

Wen et al. ${ }^{17}$ successfully synthesized TON zeolites in pure silica composition using a 1-butyl-3-methylimidazolium as OSDA, but the aluminum insertion (which could generate acidity and ion-exchange properties to the material) was difficult, resulting in less crystalline materials and when $\mathrm{Si}$ / Al molar ratio was 50, no zeolitic products were obtained. Furthermore, no characterization were available to confirm the tetrahedrally insertion of the aluminum in the zeolite framework. Using the same OSDA but employing other methodology (different reactants and crystallization mode), we are capable to synthesize highly crystalline TON zeolite with all tetrahedrally coordinated aluminum even after

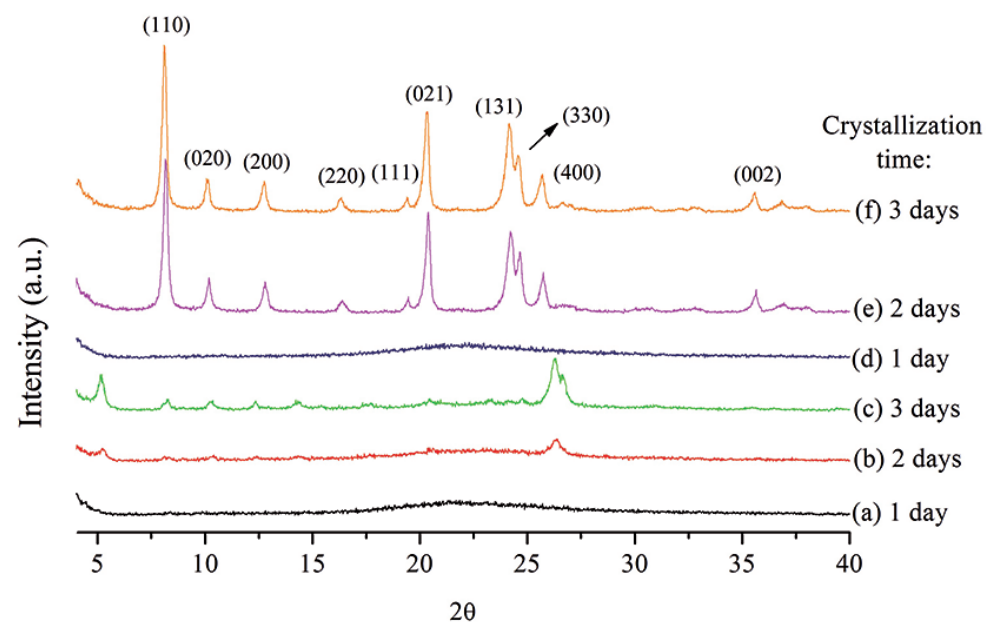

Figure 2: X-ray diffractograms of zeolites obtained by method A (using diaminooctane as OSDA) with reaction times of (a) 1 day, (b) 2 days, (c) 3 days in static mode, and (d) 1 day, (e) 2 days, and (f) 3 days with stirring. 


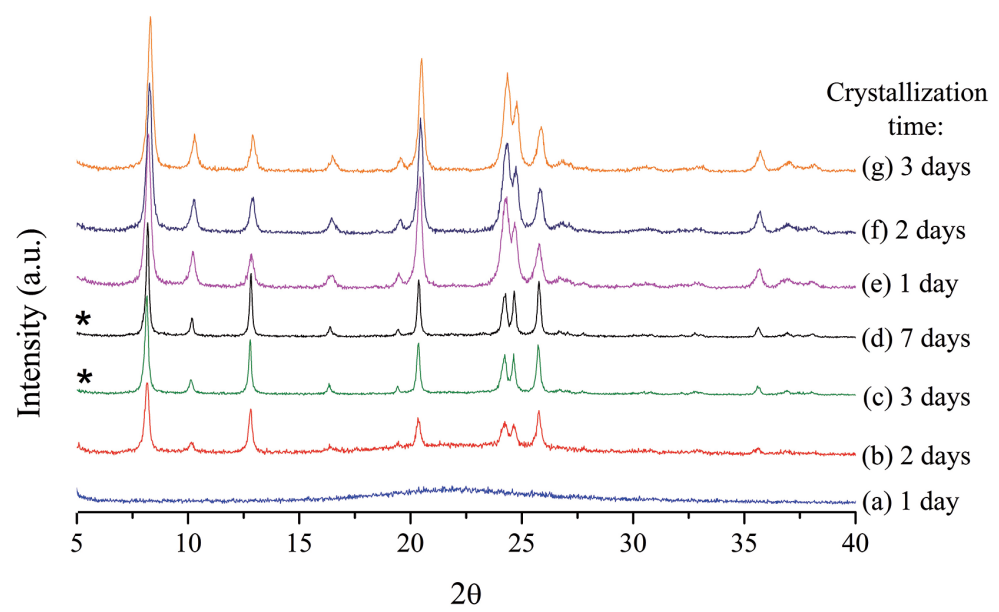

Figure 3: X-ray diffractograms of zeolites obtained by method A (using ionic liquid as OSDA) with reaction times of (a) 1 day, (b) 2 days, (c) 3 days, (d) 7 days in static mode, and (e) 1 day, (f) 2 days, (g) 3 days with stirring.

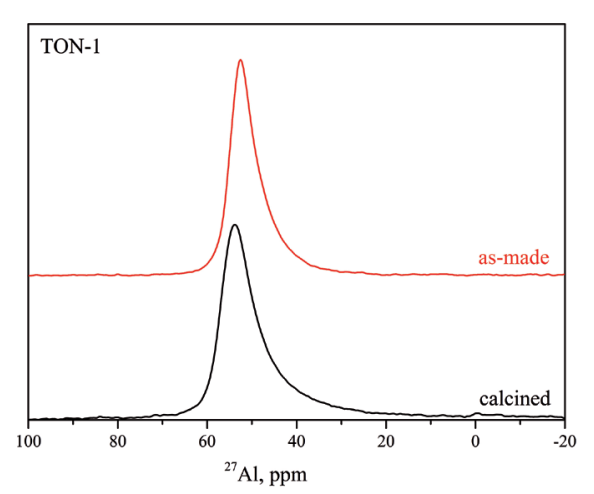

Figure 4: ${ }^{27} \mathrm{Al}$ NMR of as-made and calcined TON-1 sample obtained with ionic liquid by method $\mathrm{A}$.

calcination (TON-1 sample - obtained in 3 days in stirring - Figure 4), in a Si/Al molar ratio of 50 (gel). The final Si/ Al molar ratio for this sample after calcination was 34 (Table 1), different from the theoretical value, probably remaining silicon in solution, decreasing the synthesis yield. The same behavior was observed for another sample obtained in 7 days in static crystallization (TON-2 sample). This aluminum content correspond to $0.7 \mathrm{Al} /$ unit cell or $\sim 2 \mathrm{Al} / 3$ unit cells $\left(\mathrm{Al}_{\mathrm{n}} \mathrm{Si}_{24-\mathrm{n}} \mathrm{O}_{48}\right)$.

To verify the integrity of the ionic liquid molecule within zeolite, the TON-1 sample (not calcined) was analyzed by solid state ${ }^{13} \mathrm{C} \mathrm{CP}$ MAS NMR, and the $\left[\mathrm{C}_{4} \mathrm{MI}\right] \mathrm{Cl}$ spectrum was used for comparison (Figure 5). The spectrum of the zeolite confirms the presence of characteristic signals of the ionic liquid, indicating maintenance of the molecular structure and confirming the role of the ionic liquid as the OSDA. Elemental analysis by $\mathrm{CHN}$ was carried out and results are listed in Table 1 . The $\mathrm{C} / \mathrm{N}$ ratio in TON zeolites is very close to that in the ionic liquid $(\mathrm{C} / \mathrm{N}=4)$, confirming the integrity of the imidazolium molecule, which is in agreement with ${ }^{13} \mathrm{C}$ CP MAS NMR analysis interpretation.

The scanning electron microscopy (SEM) images of the TON zeolite samples (TON-1 and TON-2) are shown in Figure 6. The materials present needle-like morphology, being the particle sizes dependent on the crystallization mode. In static crystallization the zeolites ranging from 30 to $50 \mu \mathrm{m}$ (Figure $6 \mathrm{a}$ ). On the other hand, employing stirring the crystal size decreases to less than $2 \mu \mathrm{m}$ (Figure $6 \mathrm{~b}$ ). This can be explained by the fact that dynamic system avoids the agglomeration and intergrowth of the particles. This difference in crystal size can affect the adsorptive properties of zeolites (Table 2).

The samples discussed above (TON-1 and TON-2) were analyzed by $\mathrm{N}_{2}$ and $\mathrm{CO}_{2}$ adsorption, and their isotherms are shown in Figure 7. In contrast to the TON-1 sample, nitrogen hardly can diffuse through the channels of TON-2 in the $\mathrm{K}^{+}$ form at $-196^{\circ} \mathrm{C}$ and consequently no adsorption data can be acquired in our experimental conditions (even very long equilibration times were applied for these attempts of $\mathrm{N}_{2}$ adsorption measurements). For this reason, we exchanged the potassium cations of the zeolite by $\mathrm{H}^{+}$, to verify if the cation has any influence on the intraparticle diffusion. In fact, after the cation exchange, the analysis was able to

Table 1: Physico-chemical properties of the obtained zeolites with ionic liquid by method A.

\begin{tabular}{lcccccc}
\hline Sample & OSDA & $\mathrm{Si} / \mathrm{Al}_{\text {(final) }}$ & $\mathrm{C}(\mathrm{wt} \%)$ & $\mathrm{N}(\mathrm{wt} \%)$ & $(\mathrm{C} / \mathrm{N})_{\text {real }}{ }^{\text {a }}$ & $\mathrm{Al} / \mathrm{u} . c$. \\
\hline TON-1 - 3 days stirring & Ionic liquid & 34 & 5.85 & 1.78 & 3.84 & 0.7 \\
TON-2 - 7 days static & Ionic liquid & 34 & 4.51 & 1.37 & 3.83 & 0.7 \\
\hline
\end{tabular}

a Theoretical value for $\left[\mathrm{C}_{4} \mathrm{MI}\right] \mathrm{Cl}=4$ 


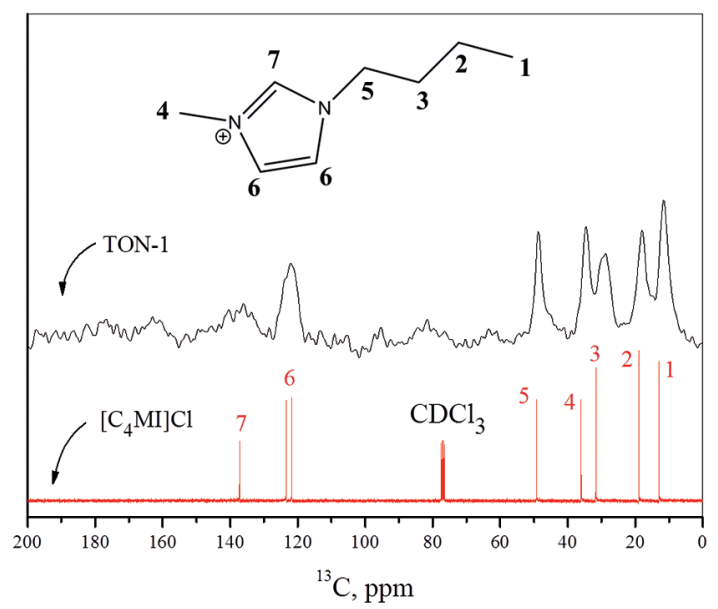

Figure 5: ${ }^{13} \mathrm{C}$ CP MAS NMR of as-prepared ionic liquid (bottom) and within the TON zeolite (top).

be performed, which proves that the nature of the cation present within zeolite influences on the adsorption features. However, even in the $\mathrm{K}^{+}$form (ionic radius, $0.133 \mathrm{~nm}$ ), TON-1 still adsorbs more nitrogen than TON-2 in the $\mathrm{H}^{+}$ form (ionic radius, $0.029 \mathrm{~nm}$ ) (Figure 7a). The $\mathrm{N}_{2}$ adsorption isotherms of both zeolites, at low relative pressures, present Type I(a) isotherms, where the amount adsorbed reaches a limiting value (plateau), characteristic of microporous materials having mainly narrow micropores (of width $<1$ $\mathrm{nm}$, for instance, TON zeolite), in agreement with the new IUPAC technical report. ${ }^{26}$ In addition, both exhibit a sharp increase in adsorbed amount of $\mathrm{N}_{2}$ at high relative pressures $\left(p / p^{0}>0.9\right)$, indicating the presence of large mesopores or macropores in these samples (perhaps due to the interparticle spaces). The above mentioned is reflected in the textural properties $\left(\mathrm{S}_{\mathrm{BET}}\right.$ and VTP) listed in Table 2. On the other hand, it is known that, at $-196{ }^{\circ} \mathrm{C}$, the rate of $\mathrm{N}_{2}$ diffusion is slow in this ultra-low pressure range, which turns difficult to measure equilibrated adsorption isotherms. To overcome this problem, $\mathrm{CO}_{2}$ adsorption at $0^{\circ} \mathrm{C}$ can be advantageous, since the $\mathrm{CO}_{2}$ diffusion at $0{ }^{\circ} \mathrm{C}$ into small pores is much faster than $\mathrm{N}_{2}$ at $-196{ }^{\circ} \mathrm{C}$. The $\mathrm{CO}_{2}$ adsorption isotherms of TON-1 and TON-2 in the $\mathrm{K}^{+}$form are shown in Figure $7 \mathrm{~b}$. The shape of isotherms is similar for the two $\mathrm{K}^{+}-\mathrm{TON}$ samples, presenting a difference in the amount adsorbed of $\mathrm{CO}_{2}$ between the TON zeolites, as already seen in $\mathrm{N}_{2}$ adsorption isotherms. With respect to the comparison of the micropore volume obtained from $\mathrm{N}_{2}$ and $\mathrm{CO}_{2}$ adsorption data, TON-1 gives the same micropore volume $\left(0.10 \mathrm{~cm}^{3} / \mathrm{g}\right)$ using both $\mathrm{N}_{2}$ and $\mathrm{CO}_{2}$. Whilst, TON-2 presents slightly different values; $0.07 \mathrm{~cm}^{3} / \mathrm{g}$ for $\mathrm{N}_{2}$ on $\mathrm{H}^{+}-\mathrm{TON}-2$ and 0.09 $\mathrm{cm}^{3} / \mathrm{g}$ for $\mathrm{K}^{+}-\mathrm{TON}-2$, respectively. This minor difference of micropore volumes can be attributed to the presence of different cation within zeolite $\left(\mathrm{H}^{+}\right.$vs $\left.\mathrm{K}^{+}\right)$. The micropore size distribution calculated using the $\mathrm{CO}_{2}$ adsorption isotherms (Figure 8) shows a unimodal micropore size of approximately $0.5 \mathrm{~nm}$ for both TON zeolites which is in very good agreement with crystallographic pore size of the TON structure $(0.57 \mathrm{~nm} \times 0.46 \mathrm{~nm}) .^{20}$ These results make us believe that the synthesized zeolites, especially TON1 , present the characteristic pore opening of TON zeolite. However, this can be hardly assessed by nitrogen adsorption studies at $-196{ }^{\circ} \mathrm{C}$ because diffusional restrictions due to the tendency of TON for crystallizing forming very large needle-shaped crystals $\left(\mathrm{K}^{+}\right.$form of TON-2). In this case, the use $\mathrm{CO}_{2}$ adsorption at $0^{\circ} \mathrm{C}$ becomes essential as it has been recently suggested in the IUPAC recommendation for porous characterization. ${ }^{26}$

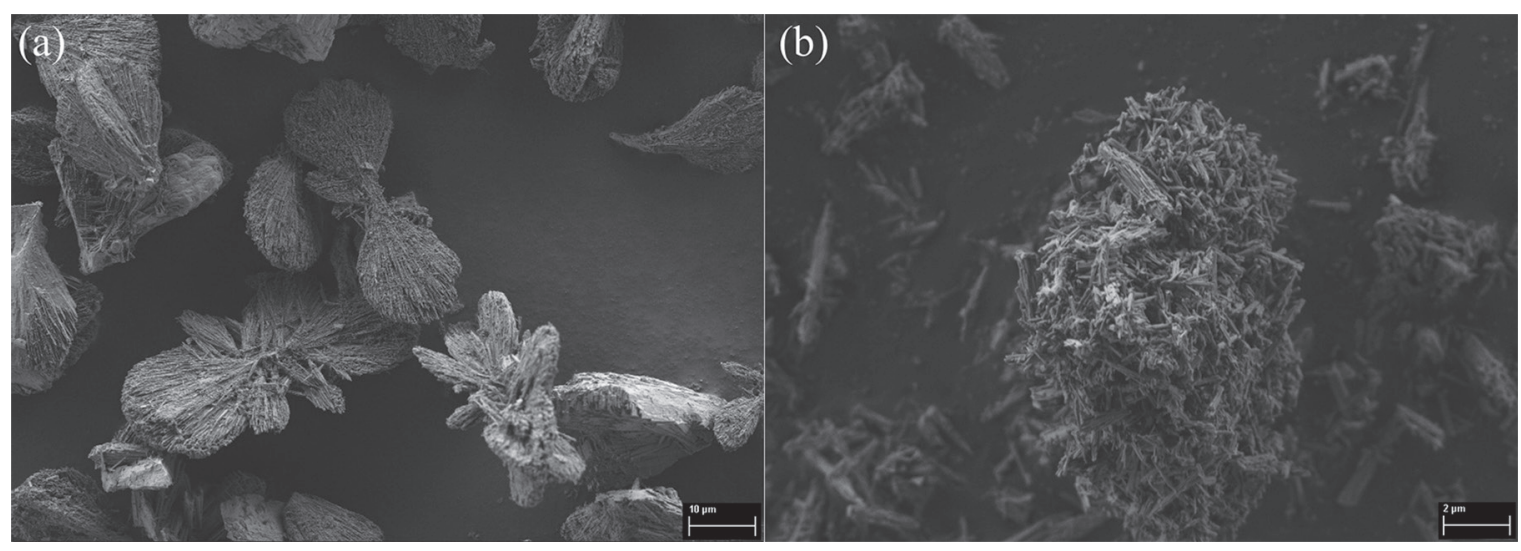

Figure 6: SEM images of samples prepared with ionic liquid by method A - (a) 7 days in static (TON-2) and (b) 3 days in stirring (TON-1).

Table 2: Textural properties of the zeolites synthesized with ionic liquid.

\begin{tabular}{lcccc}
\hline Sample & $\mathrm{S}_{\mathrm{BET}}\left(\mathrm{m}^{2} / \mathrm{g}\right)$ & $\mathrm{V}_{\mu \mathrm{p}}-\mathrm{N}_{2}\left(\mathrm{~cm}^{3} / \mathrm{g}\right)$ & $\mathrm{V}_{\mu \mathrm{p}}-\mathrm{CO}_{2}\left(\mathrm{~cm}^{3} / \mathrm{g}\right)$ & $\mathrm{TPV}\left(\mathrm{cm}^{3} / \mathrm{g}\right)$ \\
\hline TON-1 $-\mathrm{K}^{+}$form & 275 & 0.10 & 0.10 & 0.21 \\
$\mathrm{TON}-2-\mathrm{K}^{+}$form & Diffusional problems & - & 0.09 & - \\
$\mathrm{TON}-2-\mathrm{H}^{+}$form & 195 & 0.07 & - & 0.13 \\
\hline
\end{tabular}



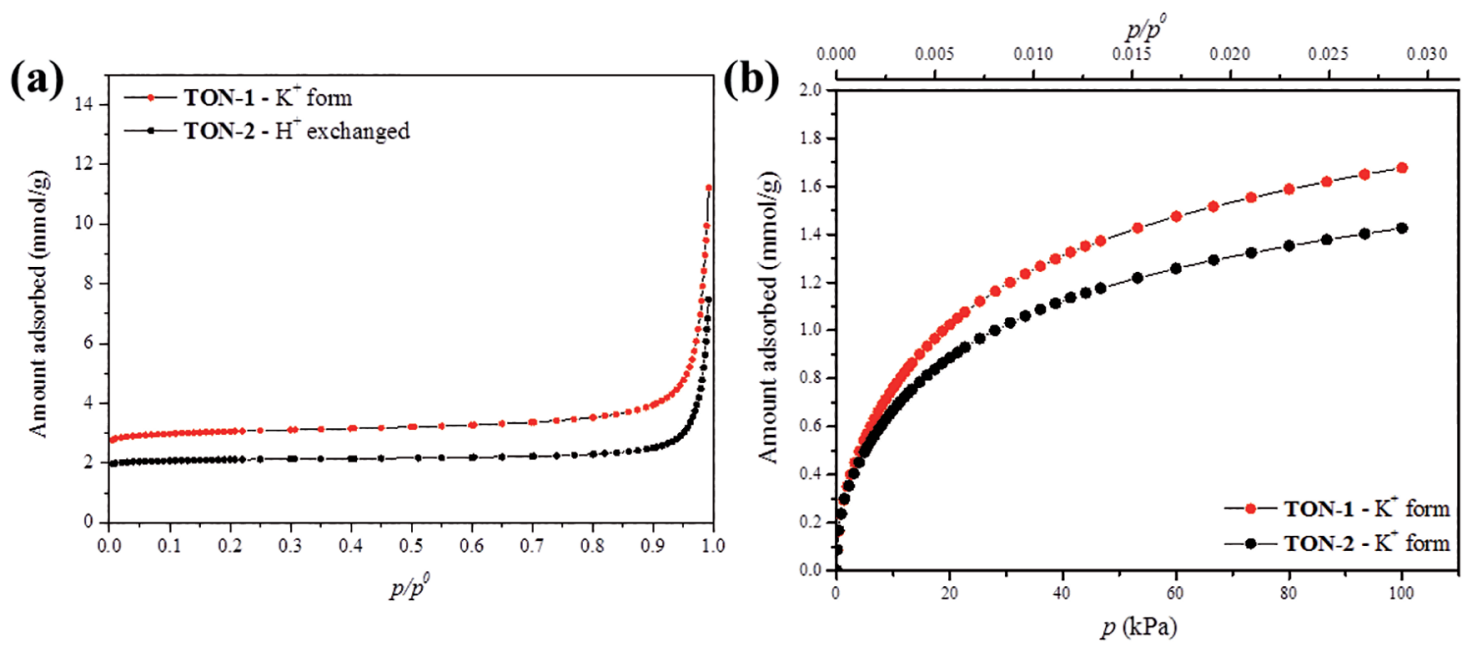

Figure 7: Adsorption isotherms of the calcined (TON-1) and (TON-2) samples: $\mathrm{N}_{2}$ at $-196{ }^{\circ} \mathrm{C}$ (a) and $\mathrm{CO}_{2}$ at $0{ }^{\circ} \mathrm{C}$ (b).

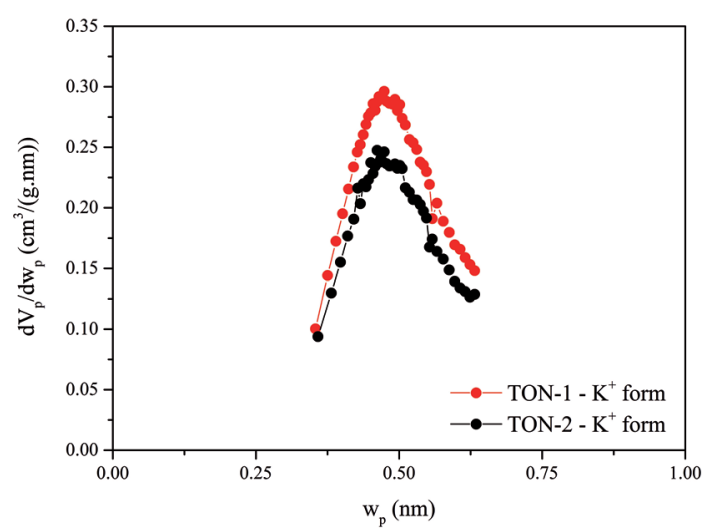

Figure 8: Micropore size distribution of TON-1 and TON-2 in $\mathrm{K}^{+}$form.
In order to study another gel composition in the crystallization of TON material, a comparative synthesis (method B) was carried out. The XRD patterns in Figure 9 show that the crystallization mode (stirring and static) in the method B strongly affects the obtained phase, as in method A, but, in this case, in terms of phase selectivity.

For static synthesis, MFI zeolites are obtained, and under stirring, the TON phase is obtained. It is possible that 1-butyl-3methylimidazolium can be accommodated in different manners in the distinct synthesis, resulting in two different zeolites. Working in fluoride media with a given imidazolium cation, Rojas et al. ${ }^{27}$ reported that the MFI zeolite is metastable to TON zeolite. Based on this result, another explanation is that static crystallization occurs slowly, and the less stable zeolite (MFI)

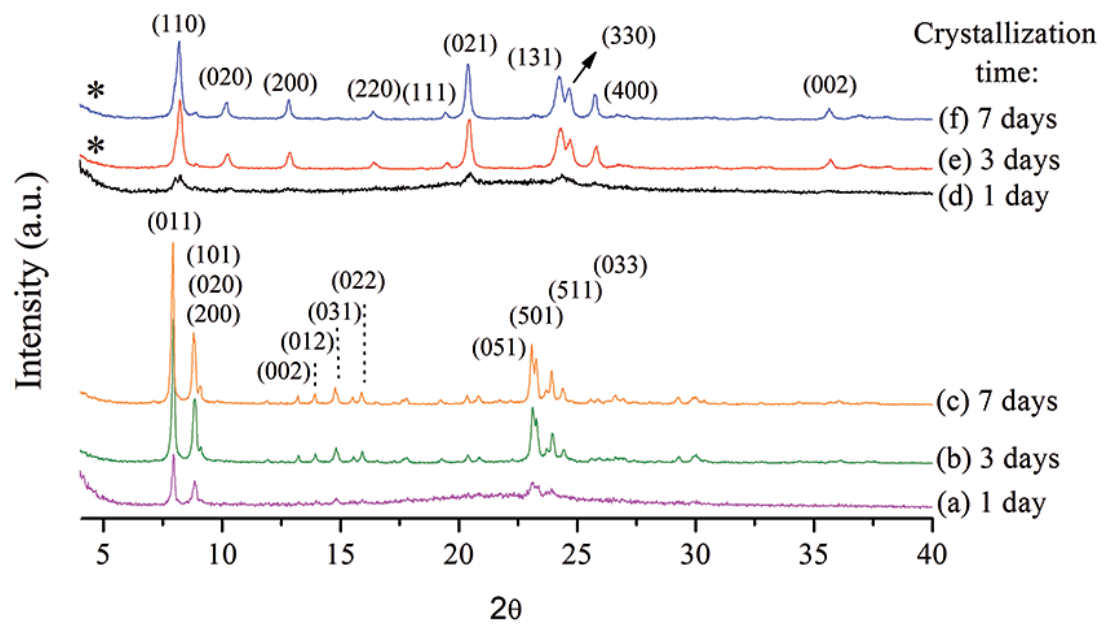

Figure 9: X-ray diffractograms of the samples synthesized using the method B with reaction times of (a) 1 day, (b) 3 days, (c) 7 days in static mode, and (d) 1 day, (e) 3 days, (f) 7 days with stirring. 


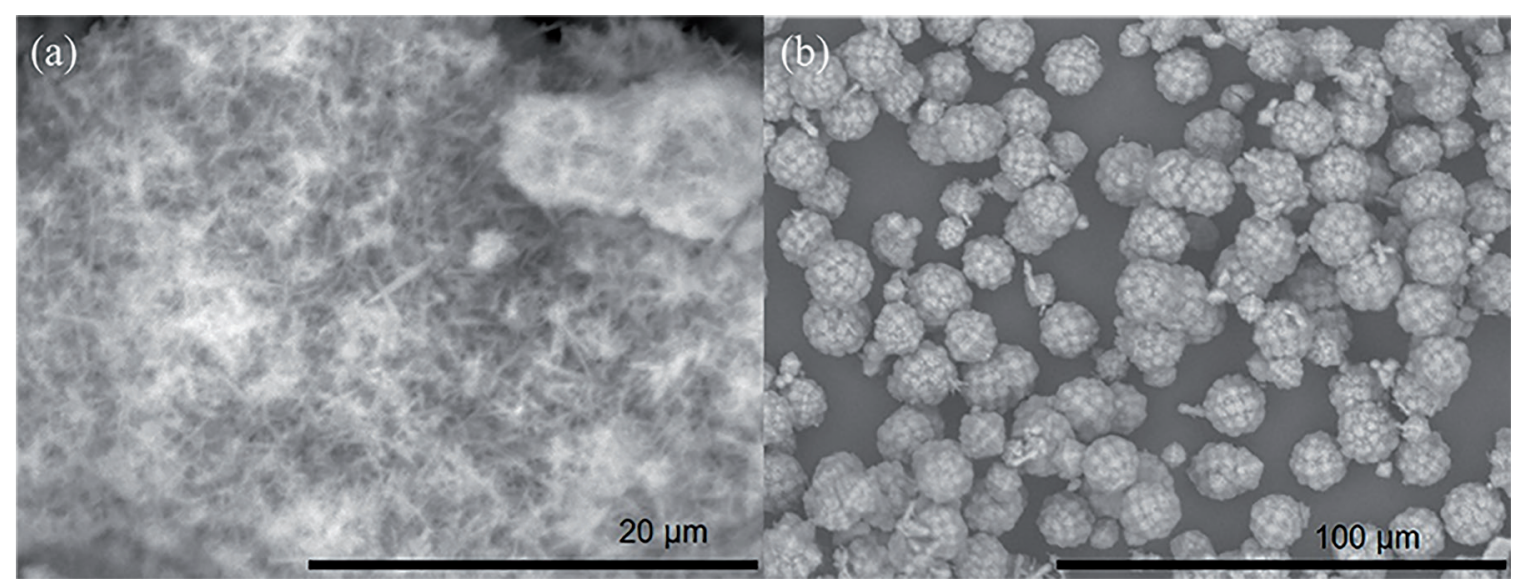

Figure 10: SEM images of samples obtained with ionic liquid by method B - (a) 3 days in stirring (TON) and (b) 3 days in static (MFI).

crystallizes. Under stirring conditions, the crystallization is faster and the TON zeolite (more stable) crystallizes. It is important highlight that comparison between different approaches (fluoride vs hydroxide-mediated synthesis) is not straightforward and one must be careful. We cannot exclude the fact that major reactants (for instance, silica source, alumina source and cation present in mineralizing agent) between synthesis $\mathrm{A}$ and $\mathrm{B}$ are different and could led to different phases. The samples of method B were also characterized in terms of SEM, and the results are presented in Figure 10. Agglomerates of zeolite crystals slightly larger than 1 $\mu \mathrm{m}$ with needle morphology are observed for the TON zeolites (Figure 10a), regardless of the condition and structure-directing agent used in the synthesis. This morphology was already observed for TON zeolites. ${ }^{28}$ MFI zeolites present interesting morphology of regular and uniform microspheres with diameters ranging between 10 and $15 \mu \mathrm{m}$ (Figure 10b). The same morphology for ZSM- 5 was obtained by Mignoni et al. ${ }^{14}$, which reports the synthesis of ZSM-5 in form of microspheres constituted by hexagonal prisms, with diameter of $35 \mu \mathrm{m}$.

\section{Conclusions}

The ionic liquid $\left[\mathrm{C}_{4} \mathrm{MI}\right] \mathrm{Cl}$ was found to be an excellent structure-directing agent for the synthesis of pure Al-TON zeolites under different crystallization conditions compared with synthesis using 1,8-diaminooctane. The aluminum incorporation was confirmed by ICP-OES and the tetrahedral coordination was confirmed by ${ }^{27} \mathrm{Al}$ NMR. The crystallization condition seems to be determinant in the morphology of the zeolite crystals, which reflect in the textural properties of the materials. MFI zeolites with interesting morphology can also be synthesized using this ionic liquid.

\section{Acknowledgments}

The authors would like to thank CAPES and CNPq for the financial support.

\section{References}

1. Sun J, Bonneau C, Cantín A, Corma A, Díaz-Cabañas MJ, Moliner M, et al. The ITQ-37 mesoporous chiral zeolite. Nature. 2009;458(7242):1154-1158.

2. Jiang J, Jordá JL, Yu J, Baumes LA, Mugnaioli E, DiazCabanas MJ, et al. Synthesis and structure determination of the hierarchical meso-microporous zeolite ITQ-43. Science. 2011;333(6046):1131-1134.

3. Gu J, Jin Y, Zhou Y, Zhang M, Wu Y, Wang J. Unseeded organotemplate-free hydrothermal synthesis of heteroatomic MFI zeolite poly-nanocrystallites. Journal of Materials Chemistry A. 2013;1:2453-2460.

4. Xie J, Wen H, Zhang W, Zhou Y, Wang J. $\mathrm{Mg}^{2+}$-derived mesoporous ultra-high silica twelve-membered-ring basic zeolites: straightforward synthesis and catalytic performance. CrystEngComm. 2016;18:1164-1173.

5. El-Roz M, Lakiss L, Vicente A, Bozhilov K, Thibault-Starzyk F, Valtchev V. Ultra-fast framework stabilization of Ge-rich zeolites by low-temperature plasma treatment. Chemical Science. 2014;5:68-80.

6. Martínez C, Corma A. Inorganic molecular sieves: Preparation, modification and industrial application in catalytic processes. Coordination Chemistry Reviews. 2011;255(13-14):1558-1580.

7. Davis ME, Lobo RF. Zeolite and molecular sieve synthesis. Chemistry of Materials. 1992;4(4):756-768.

8. Yun Y, Hernández M, Wan W, Zou X, Jordá JL, Cantín A, et al. The first zeolite with a tri-directional extra-large 14-ring pore system derived using a phosphonium-based organic molecule. Chemical Communications. 2015;51(36):7602-7605.

9. Martínez-Franco R, Cantín A, Vidal-Moya A, Moliner M, Corma A. Self-assembled aromatic molecules as efficient organic structure directing agents to synthesize the silicoaluminophosphate SAPO-42 with isolated Si species. Chemistry of Materials. 2015;27(8):2981-2989.

10. Boal BW, Zones SI, Davis ME. Triptycene structure-directing agents in aluminophosphate synthesis. Microporous and Mesoporous Materials. 2015;208:203-211. 
11. Medina ME, Platero-Prats AE, Snejko N, Rojas A, Monge $\mathrm{A}$, Gándara $\mathrm{F}$, et al. Towards inorganic porous materials by design: looking for new architectures. Advanced Materials. 2011;23(44):5283-5292.

12. Simancas R, Jordá JL, Rey F, Corma A, Cantín A, Peral I, et al. A new microporous zeolitic silicoborate (ITQ-52) with interconnected small and medium pores. Journal of the American Chemical Society. 2014;136(9):3342-3345.

13. Cundy CS, Cox PA. The hydrothermal synthesis of zeolites: Precursors, intermediates and reaction mechanism. Microporous and Mesoporous Materials. 2005;82(1-2):1-78.

14. Mignoni ML, Souza MO, Pergher SBC, Souza RF, BernardoGusmão K. Nickel oligomerization catalysts heterogenized on zeolites obtained using ionic liquids as templates. Applied Catalysis A: General. 2010;374(1-2):26-30.

15. Cooper ER, Andrews CD, Wheatley PS, Webb PB, Wormald $\mathrm{P}$, Morris RE. Ionic liquids and eutectic mixtures as solvent and template in synthesis of zeolite analogues. Nature. 2004;430(7003):1012-1016.

16. Martínez Blanes JM, Szyja BM, Romero-Sarria F, Centeno MA, Hensen EJM, Odriozola JA, et al. Multiple zeolite structures from one ionic liquid template. Chemistry A European Journal. 2013;19(6):2122-2130.

17. Wen H, Zhou Y, Xie J, Long Z, Zhang W, Wang J. Pure-silica ZSM-22 zeolite rapidly synthesized by novel ionic liquid-directed dry-gel conversion. RSC Advances. 2014;4(91):49647-49654.

18. Lopes CW, Finger PH, Mignoni ML, Emmerich DJ, Mendes FMT, Amorim S, et al. $\mathrm{TiO}_{2}$-TON zeolite synthesis using an ionic liquid as a structure-directing agent. Microporous and Mesoporous Materials. 2015;213:78-84.

19. Dupont J, Consorti CS, Suarez PAZ, Souza RF. Preparation of 1-butyl-3-methyl imidazolium-based room temperature ionic liquids. Organic Synthesis. 2002;79:236.
20. Robson H, ed. Verified syntheses of zeolitic materials. $2^{\text {nd }}$ ed. Amsterdam: Elsevier; 2001.

21. Brunauer S, Emmett PH, Teller E. Adsorption of Gases in Multimolecular Layers. Journal of the American Chemical Society. 1938;60(2):309-319.

22. Rouquerol J, Rouquerol F, Llewellyn P, Maurin G, Sing KS. Adsorption by Powders and Porous Solids: Principles, Methodology and Applications. $2^{\text {nd }}$ ed. San Diego: Academic Press; 2013.

23. Saito A, Foley HC. Curvature and parametric sensitivity in models for adsorption in micropores. American Institute of Chemical Engineers Journal. 1991;37(3):429-436.

24. Sousa-Júnior LV, Silva AOS, Silva BJB, Alencar SL. Synthesis of ZSM-22 in static and dynamic system using seeds. Modern Research in Catalysis. 2014;3:49-56.

25. Muraza O, Abdul-lateef A, Tago T, Nandiyanto ABD, Konno H, Nakasaka Y, et al. Microwave-assisted hydrothermal synthesis of submicron ZSM-22 zeolites and their applications in light olefin production. Microporous and Mesoporous Materials. 2015;206:136-143.

26. Thommes M, Kaneko K, Neimark AV, Olivier JP, RodriguezReinoso F, Rouquerol J, et al. Physisorption of gases, with special reference to the evaluation of surface area and pore size distribution (IUPAC Technical Report). Pure and Applied Chemistry. 2015;87(9-10):1051-1069.

27. Rojas A, Gómez-Hortigüela L, Camblor MA. Zeolite structure direction by simple Bis(methylimidazolium) cations: the effect of the spacer length on structure direction and of the imidazolium ring orientation on the 19F NMR Resonances. Journal of the American Chemical Society. 2012;134(8):3845-3856.

28. Asensi MA, Corma A, Martínez A, Derewinski M, Krysciak J, Tamhankar SS. Isomorphous substitution in ZSM-22 zeolite. The role of zeolite acidity and crystal size during the skeletal isomerization of $n$-butene. Applied Catalysis A: General. 1998;174(1-2):163-175. 